\title{
Combination of biomarker with clinical risk factors for prediction of severe acute kidney injury in critically ill patients
}

Lan $\mathrm{Jia}^{1,2^{*}}$ D, Xiaohua Sheng ${ }^{2,3}$, Anna Zamperetti ${ }^{2}$, Yun Xie ${ }^{2,4}$, Valentina Corradi ${ }^{2}$, Shikha Chandel ${ }^{2,5}$, Massimo De Cal ${ }^{2}$, Diego Pomarè Montin², Carlotta Caprara² and Claudio Ronco 2,6

\begin{abstract}
Background: Acute kidney injury (AKI) occurs commonly in the intensive care unit (ICU). Insulin-like growth factorbinding protein 7 (IGFBP7) and tissue inhibitor of metalloproteinase-2 (TIMP-2), known as [TIMP-2] x [IGFBP7] (NephroCheck), have been identified as novel biomarkers for the prediction of AKI risk. However, the effective use of disease biomarkers is indispensable from an appropriate clinical context. We conducted a retrospective cohort study to find risk factors and assess the performance of the combination of NephroCheck with risk factors, so as to provide feasible information for AKI prediction.

Methods: All patients who were admitted in the ICU (from June 2016 to July 2017) participated in the study. The primary outcome was the detection of severe AKI within the first 7 days after patients being admitted to the ICU. The predictors were separated into three categories: chronic risk factors, acute risk factors and biochemical indicators.

Results: The study included 577 patients. 96 patients developed to severe AKI (16.6\%) within 7 days. In addition to NephroCheck $(+)(\mathrm{OR}=2.139,95 \% \mathrm{Cl}(1.260-3.630), P=0.005)$, age $>65$ years $(\mathrm{OR}=1.961,95 \% \mathrm{Cl}(1.153-3.336), P=$ $0.013), C K D(O R=2.573,95 \% \mathrm{Cl}(1.319-5.018), P=0.006)$ and $P C T(+)(\mathrm{OR}=3.223,95 \% \mathrm{Cl}(1.643-6.321), P=0.001)$ were also the independent predictors of severe AKI within 7 days. Compared to NephroCheck (+) only (AUC $=0.66,95 \%$ Cl: 0.60-0.72), the combination of NephroCheck (+) and risk factors (age $>65$ years, CKD and PCT positive) (AUC $=0.75$, 95\% Cl:0.70-0.81) led to a significant increase in the area under ROC curve for severe AKI prediction within 7 days.

Conclusions: Although NephroCheck is an effective screening tool for recognizing high-risk patients, we found that combination with biomarker and risk factors (age > 65 years, CKD, procalcitonin positive) for risk assessment of AKI has the greatest significance to patients with uncertain disease trajectories.
\end{abstract}

Keywords: Acute kidney injury, Clinical prediction, Intensive care, Risk factors, Insulin-like growth factor-binding protein 7, Tissue inhibitor of metalloproteinase-2

\footnotetext{
* Correspondence: langirl1989@sina.com

'Department of Kidney Disease and Blood Purification, Institute of Urology \& Key Laboratory of Tianjin, The Second Hospital of Tianjin Medical University, Tianjin 300211, China

${ }^{2}$ International Renal Research Institute of Vicenza, San Bortolo Hospital, 36100 Vicenza, Italy

Full list of author information is available at the end of the article
}

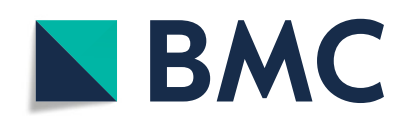

(- The Author(s). 2020 Open Access This article is licensed under a Creative Commons Attribution 4.0 International License, which permits use, sharing, adaptation, distribution and reproduction in any medium or format, as long as you give appropriate credit to the original author(s) and the source, provide a link to the Creative Commons licence, and indicate if changes were made. The images or other third party material in this article are included in the article's Creative Commons licence, unless indicated otherwise in a credit line to the material. If material is not included in the article's Creative Commons licence and your intended use is not permitted by statutory regulation or exceeds the permitted use, you will need to obtain permission directly from the copyright holder. To view a copy of this licence, visit http://creativecommons.org/licenses/by/4.0/. The Creative Commons Public Domain Dedication waiver (http://creativecommons.org/publicdomain/zero/1.0/) applies to the data made available in this article, unless otherwise stated in a credit line to the data. 


\section{Background}

Acute kidney injury (AKI) is a common clinical condition occurring in intensive care unit (ICU) patients and is confirmed as a strongly independent risk factor with high mortality. $50 \%$ of ICU patients will develop AKI and more than $20 \%$ of critically ill patients will develop to severe AKI in stage 2 and 3 (Kidney Disease: Improving Global Outcomes, KDIGO) [1]. However, AKI is usually unpredictable. For a large proportion of patients, the development of AKI has no obvious warnings or symptoms and remains clinically silent until a sudden drop of renal functions [2].

AKI could be identified by reduced urine output (urine volume $<0.5 \mathrm{~mL} / \mathrm{kg} / \mathrm{h}$ for $6 \mathrm{~h}$ ) and increased serum creatinine (SCr) level $(\geq 26.5 \mu \mathrm{mol} / \mathrm{L}$ within $48 \mathrm{~h})$, however, it has been shown to be a lagging marker [3]. Owing to the limitations of $\mathrm{SCr}$ and urine output, many efforts have been made to find biomarkers that can be used as "kidney troponin", which ideally predicts the severity and prognosis of AKI before markers of nephrological function change [4]. Therefore, many studies were conducted to discover and validate new AKI biomarkers. Until September 2014, following the publication of two multicenter ICU cohort studies, the combination of insulin-like growth factor-binding protein 7 (IGFBP7) and tissue inhibitor of metalloproteinase-2 (TIMP-2), known as [TIMP-2] x [IGFBP7] (NephroCheck), has been approved for marketing by the US Food and Drug Administration (FDA) [5-7]. This is the first biomarker used for AKI risk assessment which can help intensive care physicians and nephrologists make early predictions for AKI in intensive care settings, optimize the timing of resuscitation and promote supportive care for patients with AKI risk.

Recent research has focused on the use of biomarkers for AKI to recognize high-risk patients, however, most of these studies have not been integrated with clinical risk factors of AKI. The random and non-directional use of any biomarker will reduce its effectiveness [5, 6, 8, 9]. Basu et al. [10] have shown that combining clinical data with biomarkers can improve the accuracy of predicting severe AKI risk in pediatric ICU patients. The effective use of disease biomarkers is indispensable from an appropriate clinical context [11]. We hypothesized that the combination of the biomarker NephroCheck with risk factors would provide feasible information for the assessment of AKI and promote early intervention to improve clinical outcomes.

\section{Methods}

\section{Study population}

All patients (age $\geq 18$ years old) who were admitted in the ICU of San Bortolo Hospital (Vicenza, Italy) from June 2016 to July 2017 participated in the study. End- stage renal disease (ESRD) patients, anuria patients and patients diagnosed with severe AKI (stage 2 and 3) were excluded. This study was approved by the Ethics Committee of San Bortolo Hospital, Vicenza, Italy (Comitato Etico provinciale aULSS 8 Vicenza) (Exp. number: 03/ 17). The clinical research was conducted according to the principles expressed in the Declaration of Helsinki.

\section{Study endpoint}

The primary outcome was the detection of severe AKI (stage 2 and 3) within the first 7 days after patients being admitted to the ICU. Secondary outcomes included continuous renal replacement therapy (CRRT) initiation, ICU mortality, and length of stay (LOS). LOS means the duration of ICU stay.

\section{Data collection}

Urine samples for measuring [TIMP-2] $\mathrm{x}$ [IGFBP7] concentrations were obtained and analyzed immediately following enrollment. The concentration of two proteins ([TIMP-2] and [IGFBP7]) was analyzed with the Vitros Platform (Ortho Clinical Diagnostics) using NephroCheck Kits (Astute Medical). Another point to be noted is that the test was acquired by the central laboratory at market price. In order to develop a new diagnostic tool, the hospital allocated a special budget. Other data were collected from hospital records, including demographics, anthropometry, admission diagnosis, comorbidities, simplified acute physiology score II (SAPS II) [12] on admission, mean arterial pressure (MAP) on admission, $\mathrm{SCr}$ levels on admission, lactate levels on admission and procalcitonin (PCT) levels on admission. A single SCr was recorded per day. In addition, data on CRRT, death and ICU discharge were recorded.

\section{Definitions}

Severe AKI was defined as 2.0 or more multiplied by baseline $\mathrm{SCr}$ according to KDIGO consensus guidelines. NephroCheck $>0.3(\mathrm{ng} / \mathrm{ml})^{2} / 1000$ was considered positive and a value of $\left.\leq 0.3(\mathrm{ng} / \mathrm{ml})^{2} / 1000\right)$ was considered negative. PCT $>0.5 \mu \mathrm{g} / \mathrm{l}$ was considered positive and a value of $\leq 0.5 \mu \mathrm{g} / \mathrm{l}$ was considered negative.

\section{Risk factor profiling}

By reviewing literature [13-17], the predictors we identified were separated into three categories: chronic risk factors, acute risk factors and biochemical indicators. Chronic risk factors included advanced age (age $>65$ years), obesity $\left(\mathrm{BMI}>30 \mathrm{~kg} / \mathrm{m}^{2}\right)$, hypertension, diabetes mellitus (DM), chronic kidney disease (CKD), lung disease and cardiovascular disease (CVD). Acute risk factors were sepsis, high-risk surgery, $\mathrm{MAP}<70 \mathrm{mmHg}$, patients requiring vasopressors and mechanical ventilation. Biochemical indicators were $\mathrm{SCr}$ levels on admission, lactate levels on 
admission, Nephrocheck levels on admission and procalcitonin (PCT) levels on admission.

\section{Statistical analysis}

The percentage was calculated for category variable. Continuous variables are described as medians (interquartile range). The categorical variables between the two groups were compared using Fisher's exact test or chi-square test. The Mann-Whitney test was used in the comparison of two groups and the Kruskal-Wallis test was used in the comparison of three groups. In pretreatment step, variables were pre-screened using univariate logistic regression analysis. Once the univariate predictor of AKI is determined, then multivariate logistic regression is used to select variables, thus eliminating the collinearity and interaction of selected predictors. Comparison of the areas under the receiver operating characteristic (ROC) curve was made using the nonparametric method. $P<0.05$ was considered statistically significant. Analysis was performed using SPSS Version 24.0 (IBM Corp, Somers, NY, USA).

\section{Results}

\section{Study population}

In consecutive 866 adult patients (age $\geq 18$ years) who underwent screening, 289 unsuitable patients were excluded.
Therefore, the study included 577 patients and 96 of them developed to severe AKI (16.6\%) within 7 days in the ICU. The flowchart of this study and the number of patients are as presented in Fig. 1. Admission diagnoses for these patients included surgery (14.7\%), sepsis $(10.6 \%)$, cardiovascular disease (11.8\%), trauma (22.7\%), respiratory diseases (8.8\%), neurological diseases (21\%) and other causes (10.4\%).

\section{Patient characteristics}

Patient characteristics are listed in Table 1. Severe AKI group enrolled $96(16.6 \%)$ patients and non-severe AKI group enrolled 481 (83.4\%) patients. Compared with patients from the non-severe AKI group, patients of severe AKI group were significantly older, had a higher body mass index and more CKD, sepsis and hypotension $(\mathrm{MAP}<70 \mathrm{mmHg})$. ICU patients in severe AKI group also had a higher SCr level, lactate level, NephroCheck value and PCT level on admission.

\section{Severe AKI within seven days is associated with poor outcomes in ICU patients}

Table 1 shows $11.5 \%$ of patients in severe AKI group and $1.2 \%$ of patients in non-severe AKI group required CRRT $(P<0.001)$. Severe AKI was also associated with ICU mortality. The mortality incidence was $33.3 \%$ in severe AKI group and $13.1 \%$ in non-severe AKI group

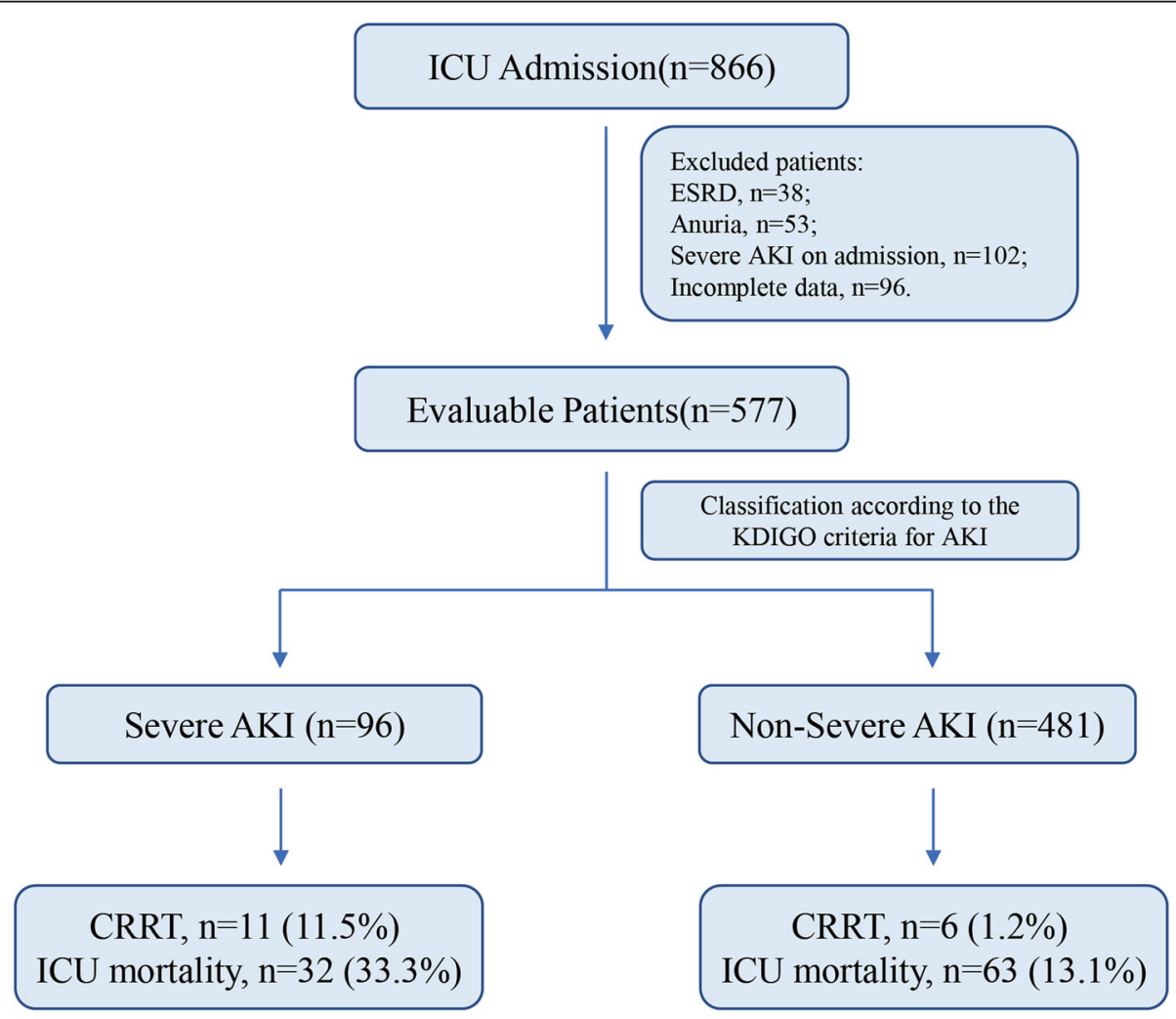

Fig. 1 The flowchart of this study and the number of patients 
Table 1 Baseline characteristics and outcomes of the study population by presence or absence of severe AKI within 7 days

\begin{tabular}{|c|c|c|c|}
\hline Variable & Severe AKI & Non-Severe AKI & $P$ Value \\
\hline $\mathrm{N}$ & $96(16.6)$ & $481(83.4)$ & \\
\hline Age (years) & $73(58-81)$ & $67(51-77)$ & 0.004 \\
\hline Male & $64(66.7)$ & $301(62.6)$ & 0.448 \\
\hline $\mathrm{BMI}\left(\mathrm{kg} / \mathrm{m}^{2}\right)$ & $26.18(23.03-29.41)$ & $24.8(22.86-27.68)$ & 0.037 \\
\hline SAPSII & $44(34-52)$ & $38(27-50)$ & 0.153 \\
\hline \multicolumn{4}{|l|}{ Chronic risk factors } \\
\hline Age $>65$ years & $66(68.8)$ & $256(53.2)$ & 0.005 \\
\hline $\mathrm{BMl}>30 \mathrm{~kg} / \mathrm{m}^{2}$ & $21(21.9)$ & $61(12.7)$ & 0.039 \\
\hline Hypertension & $48(50)$ & $212(44.1)$ & 0.49 \\
\hline DM & 21(21.9) & $66(13.7)$ & 0.138 \\
\hline CKD & $20(20.8)$ & $39(8.1)$ & $<0.001$ \\
\hline Lung diseases & $8(8.3)$ & $43(8.9)$ & 0.848 \\
\hline CVD & $10(10.4)$ & $58(12.1)$ & 0.649 \\
\hline \multicolumn{4}{|l|}{ Acute risk factors } \\
\hline Sepsis & $20(20.8)$ & $41(8.5)$ & $<0.001$ \\
\hline Surgery & 18(18.8) & $67(13.9)$ & 0.224 \\
\hline Vasopressor & $46(47.9)$ & 179(37.2) & 0.05 \\
\hline Mechanical ventilation & $71(74)$ & $329(68.4)$ & 0.281 \\
\hline $\mathrm{MAP}<70 \mathrm{mmHg}$ & $40(41.7)$ & $109(22.7)$ & $<0.001$ \\
\hline \multicolumn{4}{|l|}{ Biochemical indicators } \\
\hline Serum creatinine, admission (mg/dl) & $1.08(0.75-1.45)$ & $0.83(0.65-1.08)$ & $<0.001$ \\
\hline Serum lactate, admission (mmol/l) & $2.1(1.4-3.8)$ & $1.6(1.2-2.6)$ & 0.001 \\
\hline NephroCheck value, admission $\left((\mathrm{ng} / \mathrm{ml})^{2} / 1000\right)$ & $0.66(0.23-2.49)$ & $0.29(0.08-0.86)$ & $<0.001$ \\
\hline PCT, admission (ug/l) & $1.19(0.28-6.81)$ & $0.26(0.10-1.45)$ & $<0.001$ \\
\hline Nephrocheck (+) & 69(71.9) & 233(48.4) & $<0.001$ \\
\hline $\mathrm{PCT}(+)$ & $54(56.3)$ & 115(23.9) & $<0.001$ \\
\hline \multicolumn{4}{|l|}{ Outcomes } \\
\hline CRRT & $11(11.5)$ & $6(1.2)$ & $<0.001$ \\
\hline Death & $32(33.3)$ & $63(13.1)$ & $<0.001$ \\
\hline $\operatorname{LOS}(d)$ & $5(2-8)$ & $3(2-7)$ & 0.034 \\
\hline
\end{tabular}

Data are expressed as $\mathrm{n}(\%)$ or median (interquartile range)

BMI Body mass index, SAPS II Simplified acute physiology score II, DM Diabetes mellitus, CKD Chronic kidney disease, CVD Cardiovascular disease, MAP Mean arterial pressure, PCT Procalcitonin, CRRT Continuous renal replacement therapy, LOS Length of stay

respectively $(P<0.001)$. Severe AKI also increased LOS in ICU. LOS of severe AKI group and non-severe AKI group were $5(2-8)$ and $3(2-7)$, respectively $(P=0.034)$.

\section{Univariate variables associated with severe AKI within seven days}

Table 2 provides a list of significant univariate variables associated with severe AKI within 7 days. The presence of hypertension, CVD, lung disease, high-risk surgery, mechanical ventilation and SAPSII cannot predict the development of AKI in our study. Among all chronic risk factors, age $>65$ years, $\mathrm{BMI}>30 \mathrm{~kg} / \mathrm{m}^{2}, \quad \mathrm{DM}$ and CKD could predict severe AKI, and the relative risk was
$1.934 \quad(95 \% \quad \mathrm{CI}(1.212-3.085) \quad P=0.006),, \quad 1.887 \quad(95 \%$ CI(1.085-3.282), $\quad P=0.025), \quad 1.748 \quad(95 \%$ CI $\quad(1.009$ 3.027), $P=0.046), 2.982$ (95\% CI (1.651-5.388), $P<$ 0.001 ), respectively. Among acute risk factors, sepsis and $\mathrm{MAP}<70 \mathrm{mmHg}$ could predict severe AKI, with a relative risk of 2.824 (95\% CI $(1.570-5.081), P=0.001)$ and 2.431 (95\% CI $(1.537-3.845), P<0.001)$. Among biochemical indicators, elevated $\mathrm{SCr}$ level was associated with a relative risk of 1.697 of developing severe AKI (95\% CI (1.263-2.28), $P<0.001)$. With an increase of serum lactate concentration, the risk of developing severe $\mathrm{AKI}(\mathrm{OR}=1.115,95 \% \mathrm{CI}(1.036-1.199), P=0.003)$ would be increased by $11.5 \%$. In addition, NephroCheck 
Table $\mathbf{2}$ Logistic regression analysis for predictor of severe AKI within 7 days

\begin{tabular}{|c|c|c|}
\hline Variable & Univariate & Multivariate \\
\hline \multicolumn{3}{|l|}{ Chronic risk factors } \\
\hline Age $>65$ years & $1.934(1.212-3.085)$ & $1.961(1.153-3.336)$ \\
\hline $\mathrm{BMI}>30 \mathrm{~kg} / \mathrm{m}^{2}$ & $1.887(1.085-3.282)$ & NS \\
\hline DM & $1.748(1.009-3.027)$ & NS \\
\hline CKD & $2.982(1.651-5.388)$ & $2.573(1.319-5.018)$ \\
\hline \multicolumn{3}{|l|}{ Acute risk factors } \\
\hline Sepsis & $2.824(1.570-5.081)$ & NS \\
\hline $\mathrm{MAP}<70 \mathrm{mmHg}$ & $2.431(1.537-3.845)$ & NS \\
\hline \multicolumn{3}{|l|}{ Biochemical indicators } \\
\hline Serum creatinine, admission (mg/dl) & $1.697(1.263-2.281)$ & NS \\
\hline Serum lactate, admission (mmol/l) & $1.115(1.036-1.199)$ & NS \\
\hline Nephrocheck (+) & $2.720(1.684-4.394)$ & $2.139(1.260-3.630)$ \\
\hline $\mathrm{PCT}(+)$ & $4.883(2.625-9.084)$ & $3.223(1.643-6.321)$ \\
\hline
\end{tabular}

Data are expressed as odds ratio $(95 \% \mathrm{Cl})$. NS: Nonsignificant predictors

$B M I$ Body mass index, DM Diabetes mellitus, CKD Chronic kidney disease, MAP Mean arterial pressure, PCT Procalcitonin

$(+)$ predicts the development of severe AKI with a relative risk of 2.72 (95\% CI (1.684-4.394), $P<0.001)$. PCT $(+)$ predicts the development of severe AKI with a relative risk of 4.883 (95\% CI $(2.625-9.084), P<0.001)$.

\section{Independent predictors of severe AKI within seven days}

Multivariate logistic regression was performed with univariate variables related to severe AKI within 7 days. Following variable selection, four independent predictors, including age $>65$ years $(\mathrm{OR}=1.961,95 \%$ CI $(1.153-3.336), \quad P=$ 0.013), CKD (OR $=2.573,95 \%$ CI $(1.319-5.018), P=0.006)$, NephroCheck $(+)$ on admission $(\mathrm{OR}=2.139,95 \%$ CI (1.260-3.630), $P=0.005)$ and PCT $(+)$ on admission $(\mathrm{OR}=$ 3.223 , 95\% CI (1.643-6.321), $P=0.001)$ were used to predict the development of severe AKI (Table 2).

\section{NephroCheck level on admission was associated with incidence of severe AKI within seven days and its poor outcomes}

For 577 patients, 275 (47.7\%) were NephroCheck $\leq 0.3$ $(\mathrm{ng} / \mathrm{ml})^{2} / 1000,220$ (38.1\%) were NephroCheck (0.3-2) $(\mathrm{ng} / \mathrm{ml})^{2} / 1000$ and $82(14.2 \%)$ were NephroCheck $\geq 2(\mathrm{ng} /$ $\mathrm{ml})^{2} / 1000$. Severe AKI incidence within 7 days, CRRT initiation and ICU mortality were the highest in NephroCheck $\geq 2(\mathrm{ng} / \mathrm{ml})^{2} / 1000$ group. The incidence of severe AKI within 7 days increased from $9.8 \%$ in NephroCheck $\leq 0.3(\mathrm{ng} / \mathrm{ml})^{2} / 1000$ patients to $19.1 \%$ in NephroCheck $(0.3-2)(\mathrm{ng} / \mathrm{ml})^{2} / 1000$ patients and $32.9 \%$ in NephroCheck $\geq 2(\mathrm{ng} / \mathrm{ml})^{2} / 1000$ patients (compared with three groups, $P<0.001)$. The treatment of CRRT increased from $1.1 \%$ in NephroCheck $\leq 0.3(\mathrm{ng} / \mathrm{ml})^{2} / 1000$ patients to $2.7 \%$ in NephroCheck $(0.3-2)(\mathrm{ng} / \mathrm{ml})^{2} / 1000$ patients and $9.6 \%$ in NephroCheck $\geq 2(\mathrm{ng} / \mathrm{ml})^{2} / 1000$ patients (compared with three groups, $P<0.001$ ). ICU mortality increased from $13.5 \%$ in $\mathrm{NC}(-)$ patients to $16.8 \%$ in NephroCheck $(0.3-2)(\mathrm{ng} / \mathrm{ml})^{2} / 1000$ patients and $25.6 \%$ in NephroCheck $\geq 2(\mathrm{ng} / \mathrm{ml})^{2} / 1000$ patients (compared with three groups, $P=0.033$ ) (Fig. 2).

\section{Incorporation of risk factors augments the predictive performance of the NephroCheck}

Compared with NephroCheck $(+)$ only $(\mathrm{AUC}=0.66$, 95\% CI:0.60-0.72), the combination of NephroCheck (+) and risk factors (age $>65$ years, CKD and PCT positive) (AUC $=0.75,95 \%$ CI:0.70-0.81) led to a significant increase in the area under ROC curve for prediction of severe AKI within 7 days (Fig. 3).

\section{Discussion}

AKI is a major complication of major diseases, which is associated with poor outcomes, high mortality and increased resource use [17-19]. The recognition of patients at high risk of developing AKI has attracted more and more attention recently. Early identification of AKI allows for rapid therapeutic intervention to achieve significant clinical benefits. AKI animal models using ischemic, toxic, and septic models have shown that multiple therapeutic agents appear to reduce kidney injury if they are administered before or shortly after injury [20-23].

Cell cycle arrest may be the first process of neurological cell activation upon stress. Protein [TIMP-2] and [IGFBP7] associated with cell cycle arrest are promising markers for the detection of AKI. It has been verified that [TIMP-2] $\mathrm{x}$ [IGFBP7] is superior to other biomarkers on detecting AKI in previous cohorts studies $[5,6]$, which provide early warnings and allow physicians to modify risk, promote intervention and avoid further complications. 


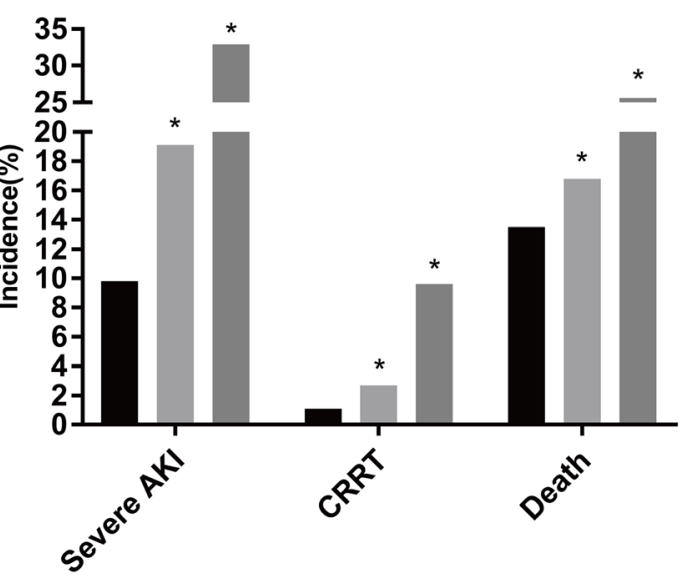

$\mathrm{NC} \leq 0.3(\mathrm{ng} / \mathrm{ml})^{2} / 1000$

$0.3<\mathrm{NC}<2(\mathrm{ng} / \mathrm{ml})^{2} / 1000$

$\mathrm{NC} \geq 2(\mathrm{ng} / \mathrm{ml})^{2} / 1000$

Fig. 2 The graph shows that NephroCheck level on admission has a positive relationship with incidence of severe AKI within seven days and its poor outcomes. NC: NephroCheck. ${ }^{*} P<0.05$

Our study demonstrated that NephroCheck is an effective screening tool for recognizing high-risk patients of AKI and it indicates that early NephroCheck (+) is a good predictor of severe AKI. In this study, we found that patients with NephroCheck $>0.3(\mathrm{ng} / \mathrm{ml})^{2} / 1000$ will significantly increase predictive discrimination against subsequent severe AKI. In addition to severe AKI, we also observed that patients with NephroCheck (+) were more likely to have other poor outcomes, such as CRRT initiation and death. Furthermore, as the level of NephroCheck increases, the risk of severe AKI and its poor outcomes also increase. NephroCheck $\geq 2(\mathrm{ng} / \mathrm{ml})^{2} /$ 1000 patients had highest incidence of severe AKI, CRRT initiation and ICU mortality within 7 days.

Although NephroCheck is a good tool for recognizing the increased risk of AKI and its poor outcomes, indiscriminate biomarker measurement in every patient, regardless of age and comorbidities, will render any test

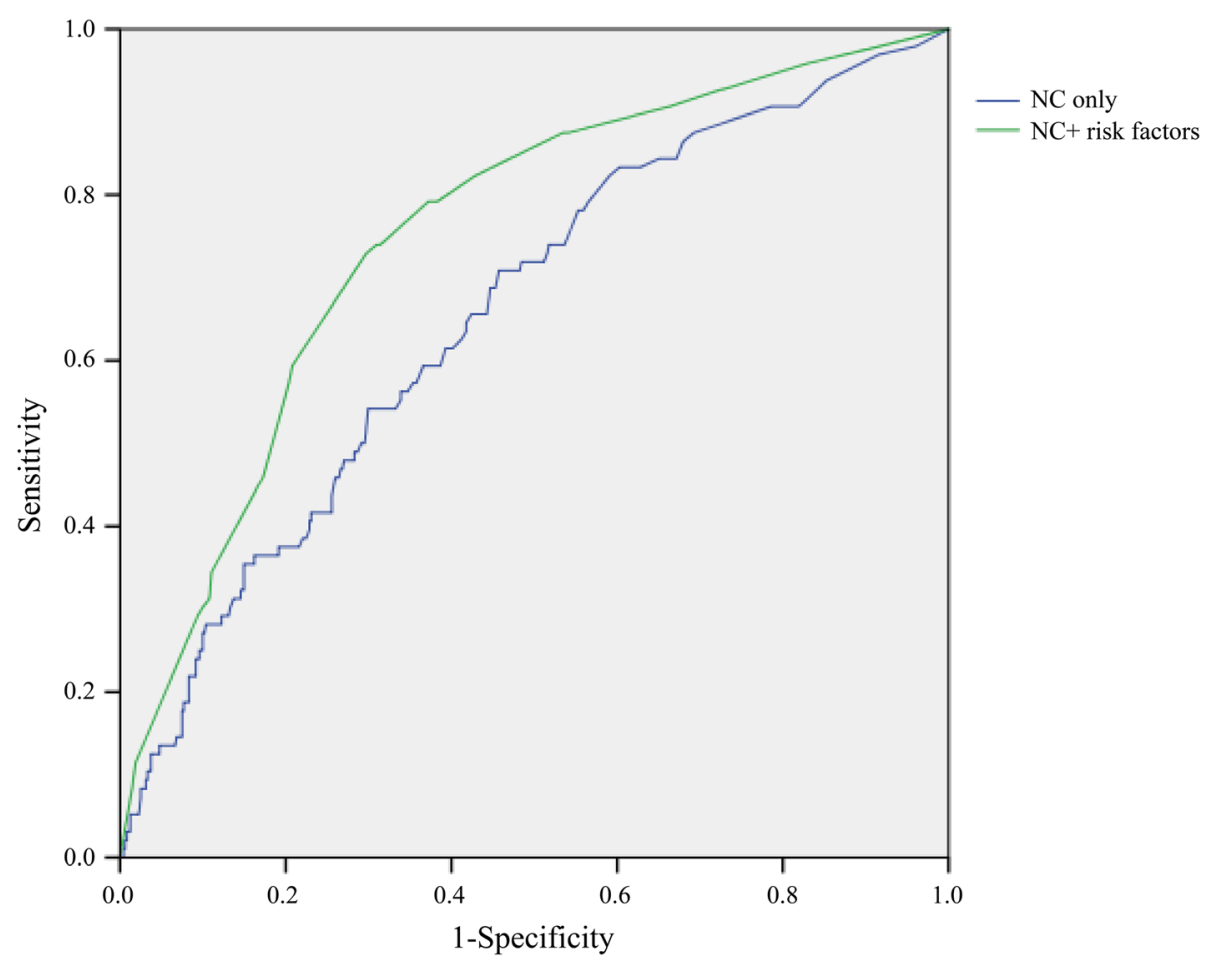

Fig. 3 The ROC curves show incorporation of clinic risk factors augments the predictive performance of the NephroCheck. NC only: NephroCheck $(+)$; NC+ risk factors: age $>65$ years, CKD, NephroCheck $(+)$ and PCT (+) 
virtually useless [24]. Therefore, integration of clinical risk factors with AKI biomarkers (kidney troponin) can increase sensitivity and discriminate power to kidney attacks [25]. In our study, we have determined predictors of severe AKI, including age $>65$ years, CKD, NephroCheck $(+)$ and PCT $(+)$. Some risk factors identified for AKI in our study are consistent with previous literature reports, including age and CKD [13, 16, 17, 26, 27]. The epidemiological association between CKD and AKI makes CKD a risk factor for AKI [13, 17]. Among various hypotheses, it is assumed that patients with CKD have lost renal self-regulation and hemodynamic stability, which explains the small changes in $\mathrm{SCr}$ level and the predisposition to subsequent damage [11].

PCT is a predictor of severe AKI in our study. PCT is closely related to the severity of systemic inflammation and bacterial infection [28]. High PCT levels have been considered a good diagnostic indicator of poor prognosis in sepsis patients [29]. Increased PCT levels in patients with pancreatitis and contrast-induced AKI are associated with the development of AKI [30, 31]. Nie et al. [32] reported that PCT can be used as a predictor of AKI for infective patients.

In this study, we found that combination with biomarker NephroCheck and risk factors for risk assessment of AKI has the greatest significance to patients with uncertain disease trajectories. Future research needs to clinically or electronically identify patients at high risk of AKI development or progression to CKD or ESRD [1,33]. We plan to develop an electronic alert system including the assessment of NephroCheck and risk factors. This risk prediction tool can automatically detect high-risk patients of AKI and help perform early management and individualized treatment of AKI [13, 34-38]. For example, patients identified to suffer high-risk AKI don't need to wait for the development of AKI, but can begin to optimize volume, adjust drug dose and avoid potential nephrotoxicity based on their AKI risk profile. The aim of the tool is to reduce the severity of AKI and decrease the number of patients requiring dialysis.

Our research also has limitations. First, our study has a small number of severe AKI events. It should be noted that we have excluded 102 patients who had already developed moderate or severe AKI on admission. All of these may reduce the morbidity of AKI. Second, we were unable to determine all risk variables associated with AKI, such as insufficient blood volume, proteinuria, bilirubinuria and exposure to nephrotoxic drugs and contrast media. Furthermore, when a family member is unable to provide a medical history, it is not always possible to determine the chronic risk factors for a comatose ICU patient. Third, the urine criterion was not applied to the diagnosis of AKI in the patient population, as urine output data were not uniformly available. This may have decreased the overall incidence of AKI diagnosis. Finally, by studying NephroCheck as a biomarker in all patients admitted to the ICU, we had a larger sample size. However, this was at the expense of not exclusively focusing on those at risk of AKI. Additionally, biomarkers can only be effectively used in an appropriate clinical context and should be used in high-risk patients of AKI to avoid excessive clinical use.

\section{Conclusions}

In this study, we have determined predictors of severe AKI, including age $>65$ years, CKD, NephroCheck (+) and PCT (+). Furthermore, we found that combination with biomarker NephroCheck and risk factors (age $>65$ years, CKD and PCT) for risk assessment of AKI has the greatest significance to patients with uncertain disease trajectories.

\section{Abbreviations \\ AKI: Acute kidney injury; ICU: Intensive care unit; KDIGO: Kidney Disease: Improving Global Outcomes; IGFBP7: Insulin-like growth factor-binding pro- tein 7; TIMP-2: Tissue inhibitor of metalloproteinase-2; SCr: Serum creatinine; FDA: Food and Drug Administration; CRRT: Continuous renal replacement therapy; LOS: Length of stay; SAPS II: Simplified acute physiology score II; MAP: Mean arterial pressure; PCT: Procalcitonin; DM: Diabetes mellitus; CKD: Chronic kidney disease; ESRD: End stage renal disease; \\ CVD: Cardiovascular disease; ROC: Receiver operating characteristic}

\section{Acknowledgements}

Not applicable.

\section{Authors' contributions}

$L J$ and $C R$ designed the study; AZ, YX, VC, MC, DPM and CC collected data; $L$, $X H S$ and $Y X$ analyzed the data; $L J$ and XHS drafted the manuscript; $L J$ and SC revised the manuscript; all authors have read and approved the manuscript.

\section{Funding}

This study was supported by Science and Technology Project of Tianjin Health Committee (Grant number: QN20030) and National Natural Science Foundation of China (NSFC) (Grant number: 81600591).

\section{Availability of data and materials}

The datasets used and analyzed during the current study are available from the corresponding author on reasonable request.

\section{Ethics approval and consent to participate}

This study was approved by the Ethics Committee of San Bortolo Hospital, Vicenza, Italy (Comitato Etico provinciale aULSS 8 Vicenza) (Exp. number: 03/ 17). The informed consent obtained from study participants was written.

\section{Consent for publication}

Not applicable.

\section{Competing interests}

All the authors declared no competing interests.

\section{Author details}

${ }^{1}$ Department of Kidney Disease and Blood Purification, Institute of Urology \& Key Laboratory of Tianjin, The Second Hospital of Tianjin Medical University, Tianjin 300211, China. ${ }^{2}$ International Renal Research Institute of Vicenza, San Bortolo Hospital, 36100 Vicenza, Italy. ${ }^{3}$ Department of Nephrology, Shanghai Jiao Tong University Affiliated Sixth People's Hospital, Shanghai 200233, China. ${ }^{4}$ Department of Nephrology, Xin Hua Hospital Affiliated to Shanghai Jiaotong University School of Medicine, Shanghai 200092, China. ${ }^{5}$ Center for Translational Research on Autoimmune and Allergic Diseases, University of Piemonte Orientale, 28100 Novara, Italy. ${ }^{6}$ Department of Nephrology, Dialysis and Transplantation, San Bortolo Hospital, 36100 Vicenza, Italy. 
Received: 3 July 2020 Accepted: 3 December 2020

Published online: 10 December 2020

\section{References}

1. Ronco C, Rizo-Topete L, Serrano-Soto M, Kashani K. Pro: prevention of acute kidney injury: time for teamwork and new biomarkers. Nephrol Dial Transplant. 2017:32(3):408-13.

2. Uettwiller-Geiger DL, Vijayendran R, Kellum JA, Fitzgerald RL. Analytical characteristics of a biomarker-based risk assessment test for acute kidney injury (AKI). Clin Chim Acta. 2016;455:93-8.

3. Srisawat N, Kellum JA. Acute kidney injury: definition, epidemiology, and outcome. Curr Opin Crit Care. 2011;17(6):548-55.

4. Ostermann M, Philips BJ, Forni LG. Clinical review: Biomarkers of acute kidney injury: where are we now? Crit Care. 2012;16(5):233.

5. Kashani K, Al-Khafaii A, Ardiles T, Artigas A, Bagshaw SM, Bell M, Bihorac A, Birkhahn R, Cely CM, Chawla LS, et al. Discovery and validation of cell cycle arrest biomarkers in human acute kidney injury. Crit Care. 2013;17(1):R25.

6. Bihorac A, Chawla LS, Shaw AD, Al-Khafaji A, Davison DL, Demuth GE, Fitzgerald R, Gong MN, Graham DD, Gunnerson K, et al. Validation of cellcycle arrest biomarkers for acute kidney injury using clinical adjudication. Am J Respir Crit Care Med. 2014;189(8):932-9.

7. US Food and Drug Administration. Letter to Astute Medical. http://www. accessdata.fda.gov/cdrh_docs/pdf13/den130031.pdf.

8. Coca SG, Yalavarthy R, Concato J, Parikh CR. Biomarkers for the diagnosis and risk stratification of acute kidney injury: a systematic review. Kidney Int. 2008;73(9):1008-16.

9. Vijayan A, Faubel S, Askenazi DJ, Cerda J, Fissell WH, Heung M, Humphreys BD, Koyner JL, Liu KD, Mour G, et al. Clinical use of the urine biomarker [TIMP-2] x [IGFBP7] for acute kidney injury risk assessment. Am J Kidney Dis. 2016;68(1):19-28.

10. Basu RK, Wang Y, Wong HR, Chawla LS, Wheeler DS, Goldstein SL. Incorporation of biomarkers with the renal angina index for prediction of severe AKI in critically ill children. Clin J Am Soc Nephrol. 2014;9(4):654-62.

11. Cruz DN, Ferrer-Nadal A, Piccinni P, Goldstein SL, Chawla LS, Alessandri E, Belluomo Anello C, Bohannon W, Bove T, Brienza N, et al. Utilization of small changes in serum creatinine with clinical risk factors to assess the risk of AKI in critically III adults. Clin J Am Soc Nephrol. 2014;9(4):663-72.

12. Le Gall JR, Lemeshow S, Saulnier F. A new simplified acute physiology score (SAPS II) based on a European/north American multicenter study. Jama. 1993:270(24):2957-63.

13. Malhotra R, Kashani KB, Macedo E, Kim J, Bouchard J, Wynn S, Li G, OhnoMachado L, Mehta R. A risk prediction score for acute kidney injury in the intensive care unit. Nephrol Dial Transplant. 2017;32(5):814-22.

14. Liano F, Pascual J. Epidemiology of acute renal failure: a prospective, multicenter, community-based study. Madrid acute renal failure study group. Kidney Int. 1996;50(3):811-8.

15. Chertow GM, Lazarus JM, Christiansen CL, Cook EF, Hammermeister KE, Grover F, Daley J. Preoperative renal risk stratification. Circulation. 1997;95(4): 878-84

16. Chawla LS, Abell L, Mazhari R, Egan M, Kadambi N, Burke HB, Junker C, Seneff MG, Kimmel PL. Identifying critically ill patients at high risk for developing acute renal failure: a pilot study. Kidney Int. 2005;68(5):2274-80.

17. Sileanu FE, Murugan R, Lucko N, Clermont G, Kane-Gill SL, Handler SM, Kellum JA. AKI in low-risk versus high-risk patients in intensive care. Clin J Am Soc Nephrol. 2015;10(2):187-96.

18. Hoste EA, Bagshaw SM, Bellomo R, Cely CM, Colman R, Cruz DN, Edipidis K, Forni LG, Gomersall CD, Govil D, et al. Epidemiology of acute kidney injury in critically ill patients: the multinational AKI-EPI study. Intensive Care Med. 2015:41(8):1411-23.

19. Bouchard J, Acharya A, Cerda J, Maccariello ER, Madarasu RC, Tolwani AJ, Liang X, Fu P, Liu ZH, Mehta RL. A prospective international multicenter study of AKI in the intensive care unit. Clin J Am Soc Nephrol. 2015;10(8): 1324-31.

20. Wang W, Falk SA, Jittikanont S, Gengaro PE, Edelstein CL, Schrier RW. Protective effect of renal denervation on normotensive endotoxemiainduced acute renal failure in mice. Am J Physiol Ren Physiol. 2002;283(3): F583-7

21. Yamasaki N, Nagano T, Mori-Kudo I, Tsuchida A, Kawamura T, Seki H, Taiji M, Noguchi H. Hepatocyte growth factor protects functional and histological disorders of $\mathrm{HgCl}(2)$-induced acute renal failure mice. Nephron. 2002;90(2):195-205.
22. Okusa MD, Ye H, Huang L, Sigismund L, Macdonald T, Lynch KR. Selective blockade of lysophosphatidic acid LPA3 receptors reduces murine renal ischemia-reperfusion injury. Am J Physiol Ren Physiol. 2003;285(3):F565-74.

23. Miyaji T, Hu X, Yuen PS, Muramatsu Y, lyer S, Hewitt SM, Star RA. Ethyl pyruvate decreases sepsis-induced acute renal failure and multiple organ damage in aged mice. Kidney Int. 2003;64(5):1620-31.

24. Stein R, Gupta B, Agarwal S, Golub J, Bhutani D, Rosman A, Eng C. Prognostic implications of normal $(<0.10 \mathrm{ng} / \mathrm{ml})$ and borderline $(0.10$ to 1 . $49 \mathrm{ng} / \mathrm{ml}$ ) troponin elevation levels in critically ill patients without acute coronary syndrome. Am J Cardiol. 2008;102(5):509-12.

25. Kellum JA, Bellomo R, Ronco C. Kidney attack. Jama. 2012;307(21):2265-6.

26. Hoste EA, Lameire NH, Vanholder RC, Benoit DD, Decruyenaere JM, Colardyn FA. Acute renal failure in patients with sepsis in a surgical ICU: predictive factors, incidence, comorbidity, and outcome. J Am Soc Nephrol. 2003;14(4):1022-30.

27. Mehta RL, Pascual MT, Gruta CG, Zhuang S, Chertow GM. Refining predictive models in critically ill patients with acute renal failure. J Am Soc Nephrol. 2002;13(5):1350-7.

28. Al-Nawas B, Shah PM. Procalcitonin, a new diagnostic and prognostic marker for severe infections. Clin Microbiol Infect. 1998:4(5):237-41.

29. Guo SY, Zhou Y, Hu QF, Yao J, Wang H. Procalcitonin is a marker of gram-negative bacteremia in patients with sepsis. Am J Med Sci. 2015; 349(6):499-504

30. Huang HL, Nie X, Cai B, Tang JT, He Y, Miao Q, Song HL, Luo TX, Gao BX, Wang $L L$, et al. Procalcitonin levels predict acute kidney injury and prognosis in acute pancreatitis: a prospective study. PLoS One. 2013:8(12): e82250.

31. Kurtul A, Murat SN, Yarlioglues M, Duran M, Ocek AH, Celik IE, Kilic A, Koseoglu C, Oksuz F, Baris VO. Procalcitonin as an early predictor of contrast-induced acute kidney injury in patients with acute coronary syndromes who underwent percutaneous coronary intervention. Angiology. 2015;66(10):957-63.

32. Nie X, Wu B, He Y, Huang X, Dai Z, Miao Q, Song H, Luo T, Gao B, Wang L, et al. Serum procalcitonin predicts development of acute kidney injury in patients with suspected infection. Clin Chem Lab Med. 2013;51(8):1655-61.

33. De Rosa S, Samoni S, Ronco C. Creatinine-based definitions: from baseline creatinine to serum creatinine adjustment in intensive care. Crit Care. 2016;20:69.

34. Porter CJ, Juurlink I, Bisset LH, Bavakunji R, Mehta RL, Devonald MA. A realtime electronic alert to improve detection of acute kidney injury in a large teaching hospital. Nephrol Dial Transplant. 2014;29(10):1888-93.

35. Wallace K, Mallard AS, Stratton JD, Johnston PA, Dickinson S, Parry RG. Use of an electronic alert to identify patients with acute kidney injury. Clin Med (Lond). 2014:14(1):22-6.

36. Parikh CR, Moledina DG, Coca SG, Thiessen-Philbrook HR, Garg AX. Application of new acute kidney injury biomarkers in human randomized controlled trials. Kidney Int. 2016;89(6):1372-9.

37. Wilson FP, Shashaty M, Testani J, Ageel I, Borovskiy Y, Ellenberg SS, Feldman HI, Fernandez H, Gitelman Y, Lin J, et al. Automated, electronic alerts for acute kidney injury: a single-blind, parallel-group, randomised controlled trial. Lancet. 2015;385(9981):1966-74.

38. Selby NM, Crowley L, Fluck RJ, Mclntyre CW, Monaghan J, Lawson N, Kolhe NV. Use of electronic results reporting to diagnose and monitor AKI in hospitalized patients. Clin J Am Soc Nephrol. 2012;7(4):533-40.

\section{Publisher's Note}

Springer Nature remains neutral with regard to jurisdictional claims in published maps and institutional affiliations. 